\title{
EFFICACY OF COMBINED USE OF XP-ENDO SHAPER AND XP-ENDO FINISHER IN CLEANING SIMULATED INTERNAL ROOT RESORPTION DEFECTS: AN IN-VITRO COMPARATIVE STUDY
}

\author{
Dalia Ali Ahmed Moukarab
}

\begin{abstract}
Aim: Evaluate the efficacy of the combined use of XP shaper and finisher in cleaning simulated internal root resorption defects in comparison to the conventional passive ultrasonic irrigation using stereomicroscope.

Materials and methods: The root canals of 90 freshly extracted human mandibular premolars were prepared using Protaper up to F4 and the teeth were split longitudinally and semicircular cavities (simulated internal root resorption cavities) were prepared in the canal wall on each half of the roots, then randomly assigned into two experimental groups $(n=40)$ according to the cleaning technique groups (A) cleaned using passive ultrasonic irrigation, group (B) cleaned using XP-endo shaper followed by XP-endo finisher, five specimens were assigned to serve as negative control and five more were assigned to serve as positive control. Colored gelatin material (CGM) was prepared and applied into the semicircular cavities except for the negative control which did not receive (CGM). The root halves were reassembled creating a circular simulated resorption cavity within the root canal. Specimens were cleaned according to the group they were assigned to except for the positive control which did not receive any further treatment. All the specimens were disassembled and the residual CGM was examined under a stereomicroscope at 10x magnification and calculated as percentage of residual CGM to total area of the IRR cavity by using image analysis software and the data were statistically analyzed with one- way ANOVA test and significance level was set at $\mathrm{P}<0.05$.
\end{abstract}

Results: None of the tested methods could completely remove the CGM from the simulated IRR cavities. Group B showed lower mean percentage of residual CGM than did group A $(\mathrm{P} 0.041<)$.

Concussion: within the limitations of this study XP-endo shaper followed by XP-endo finisher was more effective in cleaning inaccessible internal root resorption defects than PUI.

KEYWORDS: XP-endo shaper file, XP-endo finisher file, passive ultrasonic irrigation, internal root resorption

\footnotetext{
* Lecturer of Endodontics, Department of Endodontics, Faculty of Dentistry, Minia University.
} 


\section{INTRODUCTION}

Internal root resorption is a chronic inflammatory process initiating from within the pulp space characterized by progressive destruction of intraradicular dentin along the canal walls ${ }^{(1)}$. It is a relatively rare condition which leads to irregular concave area on the internal wall of the root canal (resorpative lacunae) filled with granulation tissue. The removal of such tissues is essential in management of internal resorption cases ${ }^{(2)}$. Internal root resorption (IRR) presents specific difficulty in both instrumentation and filling. The concave resorpative cavity makes it inaccessible to direct mechanical contact presenting a challenge for practitioners to totally eliminate tissues from inside this defect. ${ }^{(3)}$. for many years the use of passive ultrasonic irrigation (PUI) with sodium hypochlorite $(\mathrm{NaOCl})$ has been the treatment of choice for such cases. This procedure depends on the activation of the irrigation solution amplifying its organic tissue dissolution property and forcing more solution into the resorpative lacunae ${ }^{(4)}$.

Since then PUI has been extensively studied Topcuoglu etal $2015{ }^{\text {(5) }}$ compared efficacy of different final irrigation techniques in removal of artificial placed dentinal debris from simulated IRR cavities PUI along with self-adjustable file were found to be the most effective methods among the tested techniques.

Furthermore Niavarzi etal $2019{ }^{(6)}$ found that PUI allowed significantly more penetration of photosensitizer into infected dentinal tubules with Enterococcus Faecalis biofilm indicating not only the biological activation of the photosensitizer but more over the physical advantage of PUI which provide forcing irrigation into hard to reach root canal irregularities

Resent evolution in the field of NiTi instrument manufacturing has manipulated the metallurgical properties of NiTi via thermo-mechanical processing and heat treatments. This new generation of NiTi alloy has transformation temperature close to body temperature; allowing for the martensitic in- strument to transform to the predetermined austenitic shape ${ }^{(7,8)}$

$\mathrm{XP}$ endo shaper system is the bread of this novel and special technology ( max wire NiTi technology) were the instrument is present in malleable $\mathrm{M}$ phases structure at room temperature which shifts assuming a programmed shape when it is introduced in to the root canal and hits body temperature turning into an expanding instrument stiff enough to cut dentin. Bayram etal $2018{ }^{\left({ }^{(9)}\right.}$. described it as a snack shaped rotary nickel titanium file manufactured using martinsite- austenite electro polish- flex that applies minimum stress on dentin walls and has excellent resistance to cyclic fatigue.

Furthermore the unique adaptive core which allows the smaller central core of the file to move freely and adapt to the canal irregularities, in addition to the turbulence generated around the file which enhances the penetration of irrigants into dentinal tubules and hard to reach areas of the root canals ${ }^{(\mathbf{1 0})}$.

The novel instrument has also proven to be very efficient in chemo mechanical preparation of root canal , moreover removal of bacterial biofilms as shown in a study by Bedier etal $2018^{(11)}$ where they compared the efficacy of combination of several instruments in the removal of bacterial biofilm from root canals using confocal laser scanning electron microscopy. The authors concluded that the highest bacterial removal was recorded when i-Race and XP- finisher were used together followed by XPshaper and XP- finisher while all the other groups recorded significantly lower values.

Furthermore XP- shaper system has been tested for its efficacy in removal of smear layer in study by Al-Khafaji etal $2019^{(12)}$; where it was compared to Protaper Next and Wave One Gold. Significantly more smear layer removal was recorded with Protaper Next only in the coronal third while all three instruments showed equally effective smear layer removal in the middle and apical thirds. 
XP endo finisher is also a non- tapered NiTi instrument of the Max wire family which shows high flexibility and was manufactured to improve the effectiveness of final irrigation after root canal instrumentation. According to the manufacturer, when the instrument is placed inside the canal in the rotation mode, the A-phase shape allows the files to access and clean areas that other instruments might not have reached, without harming dentin or altering the original canal shape ${ }^{(13,14)}$.

Many studies have addressed the efficacy of XPendo finisher in different endodontic uses Keskin etal $2017^{(15)}$ evaluated its efficacy in removal of calcium hydroxide intracanal medicament from internal root resorption cavities compared to passive ultrasonic activation, Endoactivator, Canal brushes. $\mathrm{XP}$-endo finisher as well as PUI showed significantly more $\mathrm{CaOH}$ removal than did the other techniques. Furthermore El naghy etal $2017^{(16)}$ studied the ability of XP finisher to remove smear layer in curved canals in-vitro compared to several other irrigation regimens .the results revealed that XP endo finisher is very efficient in removing smear layer.

Not only was XP finisher evaluated for its ability to remove debris and smear layer but also investigated for its effectiveness on removal of biofilm in infected tooth model with artificial apical grooves in a study by Bao etal ${ }^{(17)}$ whom compared XP finish to PUI and conventional needle irrigation. The result showed that XP finisher had significant impact on removing biofilm from hard to reach areas in root canals. The null hypothesis of this study is that combined use of XP-endo shaper followed by $\mathrm{XP}$-endo finisher has no superior effect in cleaning simulated IRR cavities than dose the conventional PUI technique.

\section{AIM OF THE STUDY}

Evaluate the efficacy of the combined use of XP shaper and finisher in cleaning simulated internal root resorption defects in comparison to the conventional passive ultrasonic irrigation using stereomicroscope

\section{MATERIALS AND METHODS}

\section{Preparation of Specimens:}

A total of 90 freshly extracted human mandibular premolars with straight roots were selected for this study. The teeth were selected according to the following criteria: absence of root decay, no previous endodontic treatment, mature closed apices, absence of root resorption root length at least $15 \mathrm{~mm}$ and no visible cracks. a single canal and no calcification was confirmed using radiographic examination.

Teeth were immersed in $5.25 \%$ NaOCL for 30 minutes to remove the soft tissues. Through cleaning of external surface of all debris, soft tissue remnant and calculus using a scaler then stored in tap water containing $0.1 \%$ thymol solution to prevent bacterial growth. The crown of each tooth was partially removed using a diamond stone (Diatech; Coltene Whaledent, Switzerland) to create a standard tooth length of $20 \mathrm{~mm}$ (any sample with tooth length less than $20 \mathrm{~mm}$ were discarded and replaced) this was to ensure standardization and provide a flat reproducible reference point. Endodontic access cavities were prepared using diamond bur (Diatech; Coltene Whaledent, Switzerland).

Canal patency was checked by placing a size \#15 K- file (Mani, Tochigi, Japan) into each canal until it was visible at the apical foramen. Canals that did not allow the placement of the file into the apex or those wider than size \#20 K- file at the apex were excluded and replaced. A size $15 \mathrm{~K}$-file was then placed in the canal until it was visible at the apical foramen. The working length was determined by subtracting $1 \mathrm{~mm}$ from this measurement. All specimens were instrumented with the ProTaper rotary system (Dentsply, Maillefer, Switzerland) mounted on X-smart endomotor (Dentsply, maillefer, Switzerland) up to size F4 as the master apical file. During the preparation, the root canal was irrigated with $3 \mathrm{~mL}$ of $5.25 \%$ sodium hypochlorite $(\mathrm{NaOCl})$ solution between each file. Once the preparation was complete the root canals were irrigated with $5 \mathrm{~mL}$ of 
$17 \%$ ethylene diamine tetraacetic acid (EDTA) for $1 \mathrm{~min}$ and $5 \mathrm{~mL}$ of $5.25 \% \mathrm{NaOCl}$ for $1 \mathrm{~min}$. Then finally rinsed with $10 \mathrm{~mL}$ of distilled water and then dried with paper points.

The specimens then were fixed in modified Eppendorf vials with silicone impression material (Coltene, Whaledent, Switzerland). After removal from the impression material, grooves were prepared with a water-cooled diamond double coated diamond disc ( Eastwind diamond , Windsor, Canada) on the buccal and lingual surfaces, stopping just short of the root canal and the teeth were split along their long axis in a buccolingual direction using a chisel. Two semicircular cavities were prepared in the halves of each root canal using a 2-mm round diamond bur. The diameter of the cavity was measured using digital calipers with an accuracy of $0.01 \mathrm{~mm}$. The location of the cavities was marked at $8 \mathrm{~mm}$ from the apex in all specimens.

To simulate the granulation tissue with in the internal root resorpative cavities a colored gelatin material (CGM) was prepared by mixing 10 gram, 1 gram food color and dissolved $\mathrm{In} 50 \mathrm{ml}$ cold water then heated until a slimy form is reached. The IRR cavities were filled with the CGM The root halves were then reassembled and glued together and the apical foramen was covered with sticky wax to provide a closed end canal model and no irrigation leakage. The specimens were remounted in Eppendorf vials. Five specimens were left with no application of the colored gelatin material served as the negative control group. Five more specimens were not subjected to any further procedure after application of the colored gelatin material and served as the positive control. The remaindered 80 specimens were randomly divided into two equal experimental groups $(n=40)$ according to the final cleaning technique used.

\section{Group A:}

Forty specimens were cleaned using passive ultrasonic irrigation (PUI) $3 \mathrm{~mL}$ of $5.25 \% \mathrm{NaOCl}$ was passively agitated using a smooth IrriSafe instrument mounted on the ultrasonic device (Satelec, Acteon, Merignac Cedex, France) which was placed into the canal $1 \mathrm{~mm}$ short of the WL without touching the walls, freely vibrating in the root canal for 30 seconds in a gentle up and down movement, then repeated again in the same manner with a total of $6 \mathrm{ml}$ of $5.25 \% \mathrm{NaOCl}$ for a total time of 1 minute.

\section{Group B:}

Forty specimens were treated using XP-endo shaper followed by XP-endo finisher. The root canals were filled with $3 \mathrm{~mL} \mathrm{5.} 25 \% \mathrm{NaOCl}$ and $\mathrm{XP}$ - endo shaper mounted in a torque-controlled endodontic motor operated at $800 \mathrm{rpm}$ and $1 \mathrm{Ncm}$ torque(X-smart, Dentsply, Maillefer, Switzerland) was applied for 30 seconds using slow and gentle movements $1 \mathrm{~mm}$ short of the working length of the canal. the root canals were again filled with $3 \mathrm{~mL}$ $5.25 \% \mathrm{NaOCl}$ and $\mathrm{XP}$ endo Finisher (mounted in a torque-controlled endodontic motor operated at $800 \mathrm{rpm}$ and $1 \mathrm{Ncm}$ torque) for another 30 seconds using slow and gentle movements $1 \mathrm{~mm}$ short of the working length of the canal.

To standardize the conditions of both techniques a total of $6 \mathrm{ml}$ of $5.25 \% \mathrm{NaOCl}$ for a total time of 1 minute and at $37^{\circ} \mathrm{C}$ temperature was used. The root canals of both groups were then irrigated with $3 \mathrm{ml}$ of $17 \%$ EDTA for 30 seconds followed by 10 $\mathrm{ml}$ of distilled water as a final flush. Specimens were then removed from the Eppendorf vials and disassembled for image evaluation.

\section{Image Evaluation}

Digital images were acquired to evaluate the amount of residual colored gelatin material in the IRR cavities of each half using a digital camera (Nikon, Tokyo, Japan) mounted on a stereomicroscope (Zeiss Technival 2, Oberkochen, Germany) at $10 \times$ magnification. Images were analyzed using Adobe Photoshop software (Adobe system software, Irland) the area of residual CGM in the simulated IRR cavity was calculated in pixels 
subtracted from the whole simulated IRR cavity area in pixels count and changed into percentage. The data were tabulated and statistically analyzed.

\section{Statistical analysis}

Statistical analysis was performed with IBM SPSS statistics version 20 for windows. Statistical analysis was performed with One Way ANOVA test. The significant level was set at $(\mathrm{P}>0.05)$.

\section{RESULTS}

The mean standard deviation of percentage of the residual CGM with in the IRR cavities for the test groups (A, B) are shown in tab (1). None of the tested groups (A, B) showed complete removal of the CGM used to simulate granulation tissue with in the IRR cavity. Regarding the positive control group $(n=5)$ showed complete coverage with colored gelatin material in the IRR cavities in contrast with the negative control group $(n=5)$ which showed no material at all $(\mathrm{p}>0.001)$

Regarding group A $(n=40)$ cleaned using PUI; showed mean percentage of residual CGM $16.88 \%$ with a maximum of $41 \%$ and a minimum of $5.1 \%$. On the other hand group B $(n=40)$ cleaned using XP shaper followed by XP finisher; showed mean percentage of residual CGM $12.677 \%$ with a maximum of $30 \%$ and a minimum of $4.3 \%$ fig $(1,2,3)$ and tab (1)

TABLE (1) Numerical data show the maximum, minimum and mean percentage of area occupied by residual CGM in the simulated IRR cavities from the split root specimens for both tested groups $(\mathrm{A}, \mathrm{B})$

\begin{tabular}{|c|c|c|}
\hline & Group A & Group B \\
\hline Mean & 16.8825 & 12.6775 \\
\hline std Dev & 10.6 & 7.12 \\
\hline std Erro & 1.67 & 1.12 \\
\hline Max & 41 & 30 \\
\hline Min & 5.1 & 4.3 \\
\hline Range & 35.9 & 25.7 \\
\hline
\end{tabular}

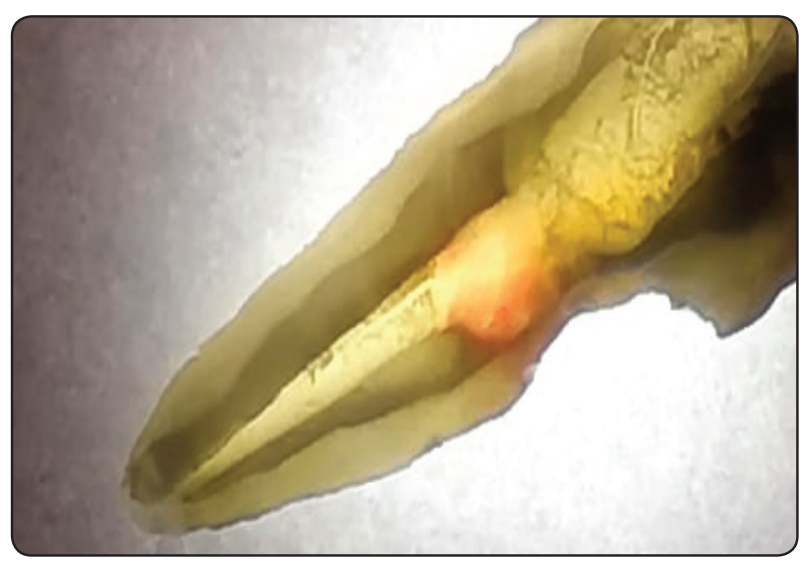

Fig. (1): Representative stereomicroscope image representing group A (using PUI) containing residual CGM in IRR cavity.

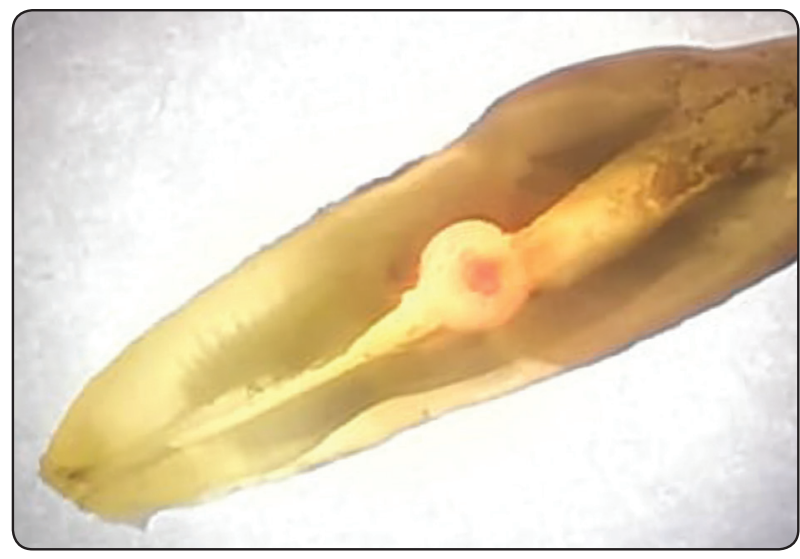

Fig. (2): Representative stereomicroscope image representing group b (using XP shaper followed by XP finisher) containing residual CGM in IRR cavity

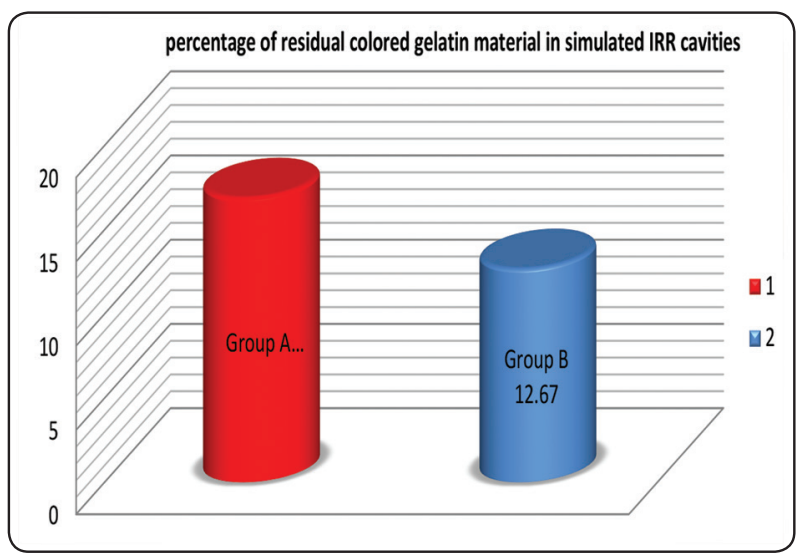

Fig. (3): Bar chart representing mean percentage of residual colored gelatin material within the simulated IRR cavities for group (A, B) 
TABLE (2): The mean and standard deviation values of percentage of residual CGM in the simulated IRR cavities for group A and group B

\begin{tabular}{|c|c|c|c|c|c|c|}
\hline Group & A & B & T value & df & Std. Error Difference & P value \\
\hline Mean & 16.8825 & 12.6775 & 2.081 & 78 & 2.02031 & $* * 0.041$ \\
\hline SD & 10.6 & 7.12 & & & & \\
\hline SEM & 1.67 & 1.12 & & & & \\
\hline $\mathrm{n}$ & 40 & 40 & & & & \\
\hline
\end{tabular}

*Statistical significance, $n$ number of specimens, SD standard deviation, A cleaning with PUI, B cleaned with XP shaper followed by XP finisher

Statistical analysis was performed with One Way ANOVA test. The significant level was set at $(\mathrm{P}>0.05)$. The results revealed statistically significant more residual colored gelatin material CGM in the simulated IRR cavities for group A than did group $\mathrm{B}(\mathrm{P}>0.041)$ indicating that using XP-endo shaper followed by XP-endo finisher remove significantly more material than conventional PUI technique $\operatorname{tab}(2)$

\section{DISCUSSION}

Internal root resorption while in fact is considered a relatively rare condition of the pulp it needs to be carefully addressed in the matters of chemo mechanical preparation and obturation procedures. The irregular concavity resultant form the resorpative process presents an instrumentation challenge, were no conventional linear moving instrument will be able to touch those concave walls $(\mathbf{1 , 2 , 3 )}$. Many methods have been researched to obtain optimum cleaning of these irregular hard to reach areas ${ }^{(4) .}$

In the present study human extracted mandibular teeth of approximately the same dimensions were selected for standardization and their bulky roots which allow for easier splitting procedure with less risk of sample corruption which has been demonstrated in previous studies ${ }^{(18,19,20)}$. Crowns were not completely decoronated to ensure space for irrigation reservoir during cleaning, Standardized cavities were prepared to simulate internal root resorption using round bur at the same level from the apex this was to create equal, uniform cavities more over to ensure they were filled with the same amount of CGM ${ }^{(22,23)}$. Regarding the present study irrigation volume and temperature and cleaning duration were standardized for all test groups. The aim of this study was to compare the effectiveness of combined use of XP-endo shaper and finisher in cleaning IRR cavities compared to PUI

Passive ultrasonic irrigation has been the treatment of choice over the years ${ }^{(4,5,6)}$. Though proven to be fairly successful method it falls short of completely removing granulation tissues from the hard to reach areas of the IRR defect (24) thus New treatment alternatives are continually been researched .

In the present study regarding the control groups 5 specimens did not receive CGM to ensure that the analysis of cleaned canal did not yield false positive of residual CGM, likewise, 5 specimens received CGM without subsequent removal to assure that CGM was uniformly present in the simulated IRR cavities and that amount initially applied was significantly different from any amounts remaining after cleaning procedure in tested groups ${ }^{(25)}$ 
In the present study, the complete removal of the colored gelatin material off the walls of the simulated IRR cavities was not obtained in any of the test groups $(\mathrm{A}, \mathrm{B})$ this was in accordance with previous studies $(\mathbf{1 0}, \mathbf{1 1}, \mathbf{1 2}, \mathbf{1 5}, 17)$

Regarding the results of the present study group A (cleaned using PUI) recorded a low Mean percentage of residual CGM at $16.88 \%$ which comes in agreement with previous studies $(4,5,6)$ Whom also found PUI to be an effective method of removing debris and smear layer, bacterial biofilm, intracanal medicaments in either normal canal configuration or simulated IRR cavities

This may be due to the irrigation agitation which creates more intense shear forces with in the fluids in root canal which increases the irrigant penetration into the tissues and through the root canal and may explain the efficacy in flushing out CGM from IRR cavities as previously described by Jiang et al ${ }^{(26)}$. Furthermore the high velocity of the irrigation flow generated by PUI leads to acoustic energy and micro-streaming effect both result in increased flushing and cleaning ability of the irrigant ${ }^{(27)}$

On the other hand concerning Group B (cleaned using XP-endo shaper followed by XP-endo finisher) a low recorded mean percentage of residual material at $12.677 \%$ was recorded which was significantly less than that of group A at $\mathrm{p}>0.05$; indicating superior cleaning ability of the XP-endo ( shaper finisher) combination. The present results are in agreement with previously conducted studies by Boa et al (28) and Hamdan et al (29) Whom found XP instruments to be more effective than PUI in removing both calcium hydroxide intracanal medicaments and bacteria 1 infections from root canals. Moreover Lacerda etal $2017{ }^{(30)}$ found XPshaper file to leave less untouched root canal walls than did any of the tested groups And Gawdat et al $2017^{(31)}$ who found XP-endo finisher to be significantly more effective than PUI in removing intracanal medicament from the apical third of the root canal.

Furthermore the results of this study are in accordance with previous study by Leoni etal ${ }^{(32)}$ where XP-finisher was more efficient in removing hard tissue debris from the apical third than did PU. The findings may be attributed to the unique max wire alloy which allows the file to expand and adapted to the different root canal configurations reaching areas conventional instruments cannot as explained by manufacturers ${ }^{(33)}$ More over it differs from PUI as it relies not only on the agitation of the irrigation solution in the root canal but rather depend on mechanical scraping of the walls, furthermore the sickle shape at the apical part of the instrument which allows for more root canal contact as found by Lacerda etal $2017{ }^{(30)}$ and in agreement with Azim etal $^{(34)}$ who reported that XPS left fewer untouched walls than did other tested instruments.

In addition to the agitation and activation of the irrigation in group B which leads to turbulence in the irrigation and amplifies its action with in the root canal as previously reported by Alves etal ${ }^{(35)}$ who observed a drop in bacterial count in infected root canals after application of XP- endo finisher

Likewise XP-endo finisher was shown to be superior in removing smear layer and hard tissue debris from root canal walls in studies by Leoni etal (32) and Elnaghy etal (16) furthermore this may be attributed to the use of combination of instruments ( XP-shaper and Finisher) compared to a single instrument PUI which comes in accordance with similar findings by Abdelhady etal 2018 (36) who showed that the combined use of XP and PUI together was more efficient in removing smear layer than each instrument used separately and which is consistent with results of Bedier etal (11) whom found the combination of XP shaper and finisher was significantly more efficient in removing $\mathrm{E}$ Faecalis from root canals than when used alone. however, results from the present study disagrees 
with those shown by Keskin etal ${ }^{(15)}$ who found no significant difference between XP and PUI in removing intracanal medicaments from resorpative defects And Wigler et al ${ }^{(37)}$ who also showed no significant difference between XP-finisher and PUI in removing calcium hydroxide from artificial grooves in the apical third of root canal Which was also confirmed by Uygun et al ${ }^{(38)}$. Thus the null hypothesis was refused.

\section{CONCLUSION:}

Within the limitations of this study XP-endo shaper followed by XP-endo finisher was more effective in cleaning inaccessible internal root resorption defects than PUI.

\section{REFERENCES}

1- Fuss Z, Tsesis I, Lin S. Root resorption -diagnosis, classification and treatment choices based on stimulation factors. Dent Traumatol. 2003; 19:175-82

2- Gabor C, Tam E, Shen Y and Haapaslo M. Prevalence of internal inflammatory root resorption. JOE. 2012; 38(1):24-7.

3- Mittal S, Kumar T, Mittal S, and Sharma J. Internal root resorption: An endodontic challenge. A case series. J Conserv Dent. 2014; 17(6):590-3.

4- Nilsson E, Bonte E, Bayet F, Lasfargues J. Management of internal root resorption permanent teeth. Int $\mathbf{J}$ of Dent. 2013; 10:7-13.

5- Topcuoglu HS, Akti A, Duzgun S, Ceyhanli KT, Topcuoglu G. effectiveness of different irrigation procedure s for removal of dentin debris from simulated internal root resorption cavity. The international journal of artificial organs. 2015 ; 38(3): 165-9.

6- Niavariz S, Pourhajibagher M, Khedmat S, Ghabraei S, Chinfoursh N, Bahador A. Effect of ultrasonic activation on the efficacy of antimicrobial photodynamic therapy: evaluation of penetration depth of photosensitizer and elimination of Enterococcus Faecalis biofilms. Photodiag and phototherapy. 2019; 27:362-6.

7- Zinelis S, Eliades T, Eliades G. A metallurgical characteristic of ten endodontic NiTi instruments: assessing the clinical relevance of shape memory and super elastic prop- erties of NiTi endodontic instruments. Int Endod J. 2010; 43:125-34.

8- Ye J and Gao Y. Metallurgical characterization of Mwire nickel titanium memory alloy used for endodontic rotary instruments during low-cycle fatigue. JOE. 2012; 38:105-7.

9- Bayram HM, Bayram E, Ocak M, Uygum AD, Celik H. effect of Protaper gold, self-adjusting file and XP-endo shaper instruments on dentinal micro crack formation: a microcomputed tomographic study. JOE. 2017; 43:1166-9.

10- Elnaghy AM, Elsaka SE. Torsional resistance of XP-endo shaper at body temperature compared with several nickel titanium rotary instruments. Int Endod J. 2018; 51:572-6.

11- Bedier MM, Hashem AA, Hassan YM. Improved dentin disinfection by combining different geometry rotary nickel titanium files in preparing root canals. Restor Dent Endod. 2018; 43(4): 46-57.

12- Al-Khafagji HA, Al-Huwaizi HF. Cleaning efficiency of root canal using different rotary instrumentation system: A comparative In-vitro study. Int J Med Res Health sci. 2019; 8(1):89-93.

13- FKG Swiss Endo. XP-endo Finisher: 3d generation. Available at: www.kkg.ch/sites/ default / files/fkg_ xp_endo_ brochure_en_vb.pdf, 2016. Accessed December 2016.

14- Vaz-Garcia ES, Leal Vieira VT, Ferreira Petitet NP, Moreira EJ, Lopes HP, Elias CN, Leal Silva EJ, Antunes HDS. Mechanical properties of Anatomic Finishing Files: XP Endo Finisher and XP-Clean. Brazilian Dental Journal. 2018; 29(2): 208-13

15- Keskin C, Sariyilmaz E, Sariyilmaz O. Efficacy of Xp-endo finisher file in removing calcium hydroxide from simulated internal resorption cavity. JOE. 2017; 43(1):126-30.

16- Elnaghy AM, Mandorah A, Elsaka SE. Effectiveness of $\mathrm{XP}$ finisher, Endoactivator and file agitation on debris and smear layer removal in curved canals. A comparative study. Odontology. 2017; 105(2): 178-83.

17- Bao P, Shen Y, Lin J, Haapasloo M. In-vitro efficacy of XP-endo finisher with 2 different protocols on biofilm removal from apical third. JOE. 2017; 43:321-5.

18- Wang H, Sanabria-Liviac D, Sleiman PH, Dorn S, Jaramillo D. Smear layer and debris removal from dentinal tubules using different irrigation protocols: scanning electron microscopic evaluation, an in vitro study. Evid Based Endod. 2017; 2:5-9. 
19- Wu MK, Vander Luis LWM, Wesselink PR. The capability of two hand instrumentation techniques to remove the inner layer of dentine in oval canals. Int Endod J 2003; 36 : 218-24.

20- Chen SH, Liu J, Dong G, et al. Comparison between ultrasonic irrigation and syringe irrigation in clinical and laboratory studies. J Oral Sci. 2016; 58: 373- 8.

21- Kamburoglu K, Kursun S, Yuksel S, Oztas B. Observer ability to detect ex vivo simulated internal or external cervical root resorption. Journal of Endodontics. 2011; 37: $168-75$

22- Keles A, Ahmetoglu F, Uzun I. Quality of different gutta-percha techniques when filling experimental internal resorptive cavities: a micro computed tomography study. Australian Endodontic Journal. 2014; 40(3):131-5.

23- Sanabria-Liviac D, Moldauer BI, Garcia-Godoy F. Comparison of the XP-endo Finisher file system and passive ultrasonic irrigation (PUI) on smear layer removal after root canal instrumentation. J Dent Oral Health. 2017:4: 1-7.

24- Van der Sluis LW, Versluis M, Wu MK, Wesselink PR. Passive ultrasonic irrigation of the root canal: a review of the literature. Int Endod J 2007; 40: 415-42.

25- Kenee DM, Allemang JD, Johnson JD, Hellstein J, Nichol BK. A quantitative assessment of efficacy of various calcium hydroxide removal techniques.JOE. 2006; 32:563-5.

26- Jiang LM, Verhaagen B, Versluis M, van der Sluis LW. Influence of the oscillation direction of an ultrasonic file on the cleaning efficacy of passive ultrasonic irrigation. $\mathrm{J}$ Endod. 2010; 36: 1372-1376.

27- Van der Sluis LW, Wu MK, Wesselink PR. The evaluation of removal of calcium hydroxide paste from an artificial standardized groove in the apical root canal using different irrigation methodologies. Int Endod J 2007; 40: 52-57.

28- Bao P, Shen Y, Lin J, Haapasalo M. In vitro efficacy of XP- 3D Finisher with two different protocols on biofilm removal from apical root canals. J Endod 2017;43: 321-5.

29- Hamdan R, Michetti J, Pinchon D, Diemer F, GeorgelinGurge M. The XP-endo Finisher for the removal of calcium hydroxide paste from root canals and from the apical third. J Clin Exp Dent 2017;9: 855-860
30- Lacerda MF, Marceliano-Alves MF, Pérez AR, Provenzano JC, Neves MA, Pires FR, Gonçalves LS, Rôças IN, Siqueira JF Jr. Cleaning and shaping oval canals with 3 instrumentation systems: a correlative microcomputed tomographic and histoligical study. JOE. 2017; 43:1878- 84

31- Gawdat S and Elkhodary S. Efficacy of XP-Endo finisher file compared to passive ultrasonic irrigation and conventional syringe irrigation on removal of triple antibiotic paste and calcium hydroxide. ENDOD PRACT. 2017;11(3):1-8.

32- Leoni GB, Versiani MA, Silva-Sousa YT, Bruniera JF, Pecora JD, Sousa-Neto MD. Ex vivo evaluation of four final irrigation protocols on the removal of hard-tissue debris from the mesial root canal system of mandibular first molars. Int Endod J. 2017; 50: 398-406.

33- FKG Dentaire SA. FKG XP-endo Shaper brochure [Internet]. La Chaux-de- Fonds: FKG Dentaire SA; c2014 [cited 2018 Aug 5]. Available from: https://www.fkg.ch / sites/default/files/201704_fkg_xp_endo_shaper _brochur _v4_fr_web.pdf. (Updated 2018 Oct 29).

34- Azim AA, Piasecki L, da Silva Neto UX, Cruz AT, Azim KA. XP Shaper, a novel adaptive core rotary instrument: micro-computed tomographic analysis of its shaping abilities. J Endod 2017; 43:1532- 8.

35- Alves FR, Andrade-Junior CV, Marceliano-Alves MF, Pérez AR, Rôças IN, Versiani MA, Sousa-Neto MD, Provenzano JC, Siqueira JF . Adjunctive steps for disinfection of the mandibular molar root canal system: a correlative bacteriologic, micro-computed tomography, and cryopulverization approach. JOE. 2016; 42:1667- 72.

36- Abdelhady Y, Refai A, Sharaan M. Cleanliness of combining XP-endo Finisher file and passive ultrasonic irrigation: an SEM study. Endod prac. 2018;12(4):257-64

37- Wigler R, Dvir R, Weisman A, Matalon S, Kfir A. Efficacy of XP-endo finisher file in the removal of calcium hydroxide paste from artificial standardized grooves in the apical third of oval root canals. Int Endod J. 2017;50: 700- 5

38- Uygun AD, Gundoğdu EC, Arslan H, Ersoy I. Efficacy of XPendo finisher and TRUShape 3D conforming file compared to conventional and ultrasonic irrigation in removing calcium hydroxide. Aust Endod J. 2016; 43(2):132-5. 